\title{
Complexation Kinetics of Copper(II) and Nickel(II) with Macrocycles: Identification of an Outer Sphere Chelate Effect
}

Nichola McCann, Geoffrey Lawrance, Yorck-Michael Neuhold, Marcel Maeder*

Department of Chemistry, University of Newcastle, Callaghan, NSW 2308, Australia

\section{Synopsis}

The complexation kinetics of three macrocyclic amine ligands with $\mathrm{Cu}$ (II) and $\mathrm{Ni}$ (II) have been determined in aqueous solution over a wide range of $\mathrm{pH}$. The resulting rate constants have been combined with a wide range of published rates for other partially protonated macrocycles. Analysis revealed a strong dependence of the rates on the charge and on the number of free donor sites on the ligands. The second observation is rationalised as an outer-sphere chelate effect.

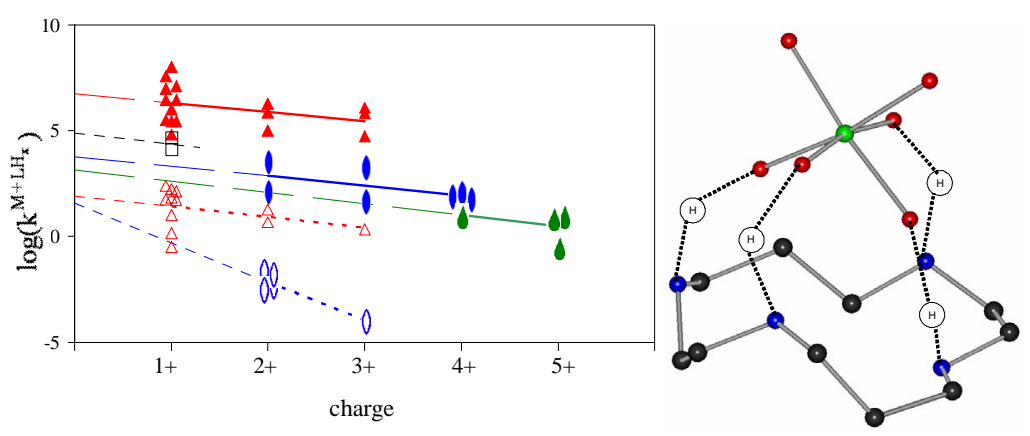

